\title{
PERANCANGAN JARINGAN HOTSPOT UNTUK PENINGKATAN LAYANAN TEKNOLOGI INFORMASI
}

\author{
Sucipto'), Teguh Andriyanto $^{2)}$, Muhammad Najibulloh Muzaki ${ }^{3)}$, Erna Daniatid), \\ Rini Indriati5), Arie Nugroho ${ }^{6}$ \\ 1,2,3,4,5)Sistem Informasi, Universitas Nusantara PGRI Kediri \\ e-mail: sucipto@unpkediri.ac.id ${ }^{1)}$,teguhae37@gmail.com²),m.n.muzaki@gmail.com ${ }^{3)}$, \\ ernadaniati@unpkediri.ac.id ${ }^{4)}$, rini.indriati@unpkediri.ac.id ${ }^{5)}$, arienugroho@unpkediri.ac.id ${ }^{6}$
}

\begin{abstract}
Abstrak : Peranan komunikasi jaringan sangat penting pada era ini yang merupakan era industri 4.0. Pada era ini menekankan pada pola digital economy, artificial intelligence, big data, robotic, dan lain sebagainya atau dikenal dengan fenomena disruptive innovation. Sarana teknologi yang perlu dikembangkan bukan langsung menginginkan teknologi otomatisasi yang canggih, namun harus diperhatikan infrasturtur jaringan yang tersedia pada suatu instansi atau wilayah yang ingin mencapai era industri 4.0. Pada obyek penelitian tengah mengembangkan arsitektur jaringan komputer. Kondisi Jaringan saat ini tercampur antara jaringan private dan jaringan publik. Hal tersebut membuat seringnya tabrakan data ketika mengakses aplikasi SIMRS. SIMRS merupakan aplikasi manajemen rumahsakit. Penelitian ini bertujuan Tujuan perancangan jaringan ini adalah membuat topologi jaringan private dan jaringan publik. Pemecahan jaringan private dengan jaringan public untuk mengoptimalkan kecepatan akses aplikasi SIMRS. Selain itu juga memperbaiki pengelolaan jaringan publik berupa manajemen hotspot. Hasil penelitian yang didapatkan yaitu akses terhadap aplikasi SIMRS tidak terganggu jaringan hostpot public dan tidak terjadi lagi tabrakan data antar jaringan public dan jaringan private.
\end{abstract}

Kata Kunci-jaringan publik, jaringan private, hotspot, topologi

Abstract : The role of network communication is significant in this era which is the industrial era 4.0. In this era, the emphasis on digital economic patterns, artificial intelligence, big data, robotics, and so on or known as the phenomenon of disruptive innovation. Technology facilities that need to be developed do not directly want sophisticated automation technology. Still, network infrastructure that is available in an agency or region that wants to reach the industrial era must be considered. The object of research is developing a computer network architecture. Current network conditions are mixed between private networks and public networks. This makes frequent data collisions when accessing the SIMRS application. SIMRS is a hospital management application. This research aims at designing the network is to make the topology of private and public networks. It is solving private networks with public networks to optimise the access speed of SIMRS applications. It also improves public network management in the form of hotspot management. The research results obtained are access to the SIMRS application is not interrupted by the public hotspot network, and data collisions do not occur again between public networks and private networks.

Keywords - public network, private network, hotspot, topology

\section{Pendahuluan}

$\mathrm{P}$ ERANAN komunikasi jaringan sangat penting pada era ini yang merupakan era industri 4.0. Pada era ini menekankan pada pola digital economy, artificial intelligence, big data, robotic, dan lain sebagainya atau dikenal dengan fenomena disruptive innovation. Dasar terselenggaranya era industri 4.0 dengan adanya sarana dan prasarana dalam teknologi yang memadai. Sarana teknologi yang perlu dikembangkan bukan langsung menginginkan teknologi otomatisasi yang canggih, namun harus diperhatikan infrasturtur jaringan yang tersedia pada suatu instansi atau wilayah yang ingin mencapai era industri 4.0.

Rumah Sakit Umum Daerah (RSUD) Gambiran merupakan rumah sakit milik pemerintah daerah Kota Kediri, yang secara historis di bangun oleh bangsa Belanda pada tahun 1875 dan mulai dikembangkan pada tahun 1928 dan merupakan rumah sakit yang pertama di Daerah Karesidenan Kediri, sehingga pada waktu itu menjadi pusat rujukan kesehatan penduduk daerah - daerah sekitarnya di Karesidenan Kediri. Mulai 
bulan Oktober 2017 RSUD Gambiran telah menempati gedung baru yang berada di JL.Kapt. Piere Tendean Kota Kediri,yang proses relokasinya terbagi menjadi beberapa tahap. Tahap pertama dilakukan relokasi unit rawat jalan/poliklinik,apotek,keuangan,kantor administrasi,dan manajerial.Dan pada tanggal 12 Maret 2018 RSUD Gambiran Kota Kediri sudah beroperasi penuh di Gedung Baru di JL.Kapt.Piere Tendean No. 16 Kota Kediri.

RSUD Gambiran sedang mengarah ke industri 4.0. Teknologi tersebut digunakan untuk peningkatan layanan terhadan pasien. Teknologi seyogyanya dapat membantu seluruh lapisan bidang seperti pendidikan, kesehatan, ekonomi, kemanusiaan, dll. Program penelitian yang dilakukan oleh prodi Sistem Informasi Universitas Nusantara PGRI ini bertujuan untuk menganalisa dan menerapkan standar dasar kebutuhan insfrastruktur jaringan yang ada di RSUD Gambiran[1].

Kondisi perpindahan RSUD gambiran dari wilayah barat kota kediri ke wilayah timur kota kediri tidak dapat langsung diikuti perpindahan kondisi infrastruktur jaringan yang memadai. Kondisi infrastruktur jaringan yang kurang memdai disebabkan lokasi yang berbeda dan luas bangunan yang jauh berbeda. Bagunan gedung rumah sakit yang baru terdiri atas empat lantai. Kerumitan pemetaan jaringan antara jaringan akses publik yang digunakan oleh pengunjung rumah sakit dan akses jaringan oleh pegawai rumah sakit menjadi fokus pada program penelitian ini.

Peraturan Menteri Kesehatan No 82 Tahun 2013 mewajibkan setiap rumah Sakit untuk menyelenggarakan Sistem Informasi Manajemen Rumah Sakit (SIMRS) untuk meningkatkan efisiensi, efektivitas, profesionalisme, kinerja, serta akses dan pelayanan Rumah Sakit. Pendukung layanan SIMRS diantaranya tersedia jaringan komputer yang memadai. Layanan jaringan komputer umumnya terbagi menjadi dua, yait terdiri dari jaringan publik dan jaringan private. Jaringan publik merupakan jaringan yang digunakan untuk layanan umum Hotspot seperti pengunjung pasien atau pengunjung rumah sakit secara umum. Jaringan Private merupakan jaringan yang digunakan kebutuhan pegawai diantaranya aplikasi SIMRS. Keberhasilan implementasi SIMRS salah satunya ditentukan oleh jaringan komputer yang stabil dan tidak digunakan berbagai koneksi selain jaringan tersebut. Semakin baik kinerja pengelolaan jaringan komputer, semakin lancar koneksi SIMRS dalam mendukung pelayanan kesehatan di Rumah Sakit.

Rumah Sakit Umum Daerah (RSUD) Gambiran Kediri telah menerapkan pengelolaan jaringan komputer dengan memisah antara jaringan private dan jaringan publik hotspot untuk keperluan SIMRS. Impelentasi manajemen jaringan hotspot masih belum optimal, terdapat beberapa titik yang masih mengambil jaringan private. Untuk dapat terus menerus memberikan layanan kesehatan terbaik kepada masyarakat, terutama layanan pada bidang teknologi informasi yang tercermin pada aplikasi SIMRS dan layanan publik hotspot. RSUD Gambiran Kediri perlu mengelola jaringan private dan jaringan publik lebih optimal lagi. Rekomendasi hasil rancangan desain topologi jaringan independen ini dapat menjadi rujukan untuk melakukan langkah-langkah perbaikan pengelolaan jaringan komputer untuk mengoptimalkan layanan koneksi jaringan SIMRS dan hotspot sehingga pengelolaan operasional layanan SIMRS dapat memenuhi standar layanan teknologi informasi yang ada.

\section{TINJAUAN PUSTAKA}

Jaringan komputer adalah "Jaringan kombinasi perangkat keras, perangkat lunak, dan pengkabelan (cabling), yang memungkinkan berbagai alat komputasi berkomunikasi satu sama lain[2]. Salah satu perangkat untuk menghubungkan jaringan computer dengan perangkat Wireless atau terjemahan kasarnya "tanpa kabel". Wireless merupakan teknologi komunikasi yang memanfaatkan gelombang radio sebagai media untuk pertukaran data[3]. Jaringan tanpa kabel ini dikenal sebagai jaringan telekomunikasi, dan banyak digunakan dalam jaringan komputer baik untuk jarak kurang dari 3 meter menggunakan bluetooth maupun pada jarak yang sangat jauh menggunakan satelit.

Manajemen wireless akan lebih optimal jika menggunakan router, salah satu router yaitu Mikrotik. Mikrotik didirikan tahun 1995 bertujuan mengembangkan sistem ISP dengan wireless. Mikrotik saat ini telah mendukung sistem ISP dengan wireless untuk jalur data internet di banyak negara, antara lain Iraq, 
Kosovo, Sri Lanka, Ghana dan banyak negara lainnya. Internet adalah sebuah jaringan komputer global, yang terdiri dari jutaan komputer yang saling berhubungan dengan menggunakan protokol yang sama untuk berbagi informasi secara bersama [4]. Berbagai pengembangan Mikrotik telah dilakukan untuk optimasi jalur data hingga saat ini dengan tersedianya perangkat lunaksistem operasi router versi lanjutan yang menjamin kestabilan, kontrol, dan fleksibilitas pada berbagai media antar muka, sistem routing dengan optimasi download. Download adalah proses transmisi sebuah file dari sebuah sistem komputer ke sistem komputer lainnya. Dari internet, user yang melakukan proses download meminta atau request sebuah file dari sebuah komputer lain (web site atauserver) dan menerimanya. Secara umum dapat diartikan bahwa downloadadalah untuk menerima atau mengambil file[5]. Penggunaan Mikrotik juga menjalankan sebuah ISP kecil, sebagai media percobaan untuk pengembangan RouterOS software[6].

Pada proses perancangan sistem, dibuatlah kerangka kerja dalam bentuk skema. Metodologi penelitian dijadikan panduan untuk menentukan tahap-tahap yang harus dilakukan.

1. Observasi Lokasi pemetaan jaringan ke-1.

2. Persiapan Alat dan bahan tambahan yang dibutuhkan dalam pelaksanaan.

3. Penyampaian hasil pemetaan jaringan untuk pelaksanaan konfigurasi baru pada jaringan publik lantai 1

4. Melakukan pelabelan kabel jaringan

5. Melakukan konfigurasi router mikrotik 1 (baru)

6. Melakukan Konfigurasi ulang Modem 2 untuk akses publik dan akses private

7. melakukan konfigurasi akses wifi layanan publik ke mikrotik 1 (baru)

8. Uji coba akses wifi publik yang telah dikonfigurasi menggunakan mikrotik 1 (baru)

\section{Metode Penelitian}

Metode yang digunakan dala penelitian ini mengunakan Network Development Life Cycle (NDLC)[7]. Network Design Life Cycle (NDLC) merupakan metode yang dapat meningkatkan perencanaan strategi peranjangan Jaringan komputer. NDLC turunan dari Analisis Sistem dan Desain Life Cycle (SDLC). Alur pada metode NDLC Pada gambar 1.

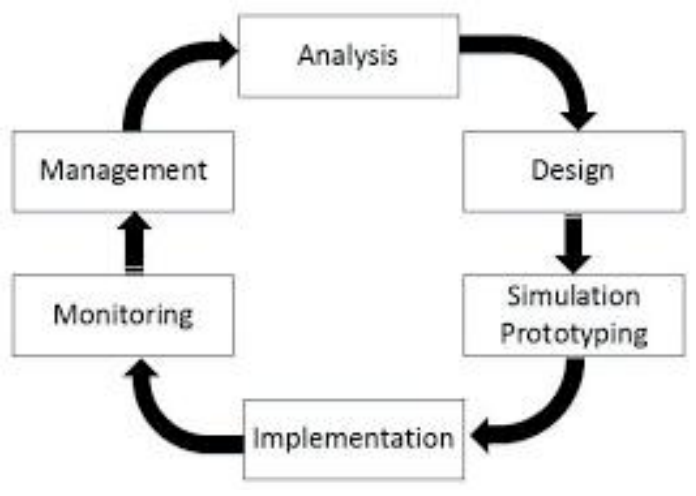

Gambar 1. Metode NDLC

Tahapan Analysis merupakan tahapan awal yang digunakan sebagai analisa kebutuhan jaringan, analisa permasalahan jaringan dan organisasi dan analisa topologi jaringan yang digunakan oleh obyek penelitian.

Tahapan Design merupajan tahapan yang didapatkan dari analisa ang digambarkan berupa design topology jaringan yang memberikan gambaran seutuhnya dari kebutuhan jaringan yang ada. Desain pada penelitian ini menggunakan Aplikasi Packet Tracert.

Tahapan Simulation Prototype merupakan simulasi perancangan jaringan hasil dari desain yang telah dibuat. Simulasi menggunakan aplikasi Packet tracert. Simulasi digunakan untuk melihat kinerja awal dari jaringan yang dibagun sudah sesuai dengan presentasi tahapan desain. 
Tahapan Implementation merupakan penerapan dari hasil simulasi. Pada penerapan penelitian ini menggunakan Router Mikrotik. Tahapan ini sangat menentukan dari keberhasilan penelitian yang dilakukan.

Tahapan Monitoring merupakan tahapan setelah implementasi jaringan. Pada tahapan ini monitoring hasil konfigurasi jaringan. Pada tahapan ini menggunakan tools dari mikrotik yaitu winbox. Parameter Monitoring yaitu komunikasi jaringan komputer yang telah dirancang dapat berjalan sesuai dengan desain jaringan pada Packet Tracert.

Tahapan Management merupakan kebijakan mengenai Policy. Pada tahapan ini Pengegang Policy yaitu administrator jaringan atau IT Manager/Networking pada obyek penelitian ini bertanggungjawab langsung atas penerapan jaringan yang telah dilakukan. IT Manager/Networking perlu membuat membuat / mengatur agar sistem yang telah dibangun dan berjalan dengan baik dapat berlangsung lama dan unsur Reliability terjaga. Policy akan sangat tergantung dengan kebijakan level management dan strategi bisnis perusahaan tersebut. IT sebisa mungkin harus dapat mendukung atau alignment dengan strategi bisnis perusahaan.

\section{A. Topologi Jaringan}

\section{HASIL DAN PEMBAHASAN}

Pelaksanaan penelitian di RSUD Gambiran dilakukan selama 3 bulan. Program penelitian ini dilakukan untuk membantu pihak instansi memperlancar akses internet dari segi internal maupun eksternal (pengunjung). Langkah awal dilakukan observasi. Observasi dilakukan dengan cara pengamatan dan hasil paparan diskusi dengan pihak instansi. Hasil yang di dapat digambarkan pada gambar 2 .

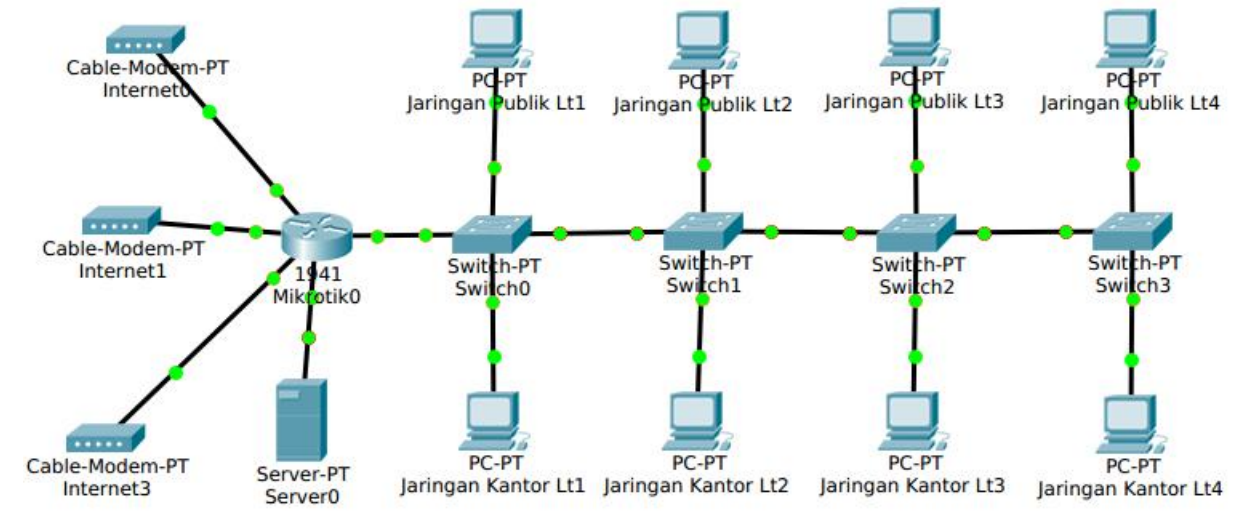

Gambar 2. Hasil Observasi Jaringan Awal RSUD Gambiran II

Hasil observasi menunjukkan bahwa jaringan yang ada di RSUD Gambiran II tidak sesuai dengan standar jaringan pada umumnya. Hal tersebut diketahui bahwa akses layanan publik dan private tercampur dalam satu switch. Switch merupakan alat yang digunakan untuk mendistribusikan IP Address pada satu jaringan. Walaupun dalam penggunaannya switch dapat digunakan untuk mendistribusikan beberapa IP Address yang berbeda jaringan, namun akan terdapat kendala-kendala. Kendala sebenarnya sudah dirasakan oleh pihak instansi, yaitu jaringan tidak stabil, akses internet maupun intranet menjadi lambat, koneksi terputus.

Hasil observasi diketahui bahwa konfigurasi yang telah dilakukan sebelumnya menggunakan dua jaringan. Jaringan tersebut adalah jaringan kantor dan jaringan wifi publik. Jaringan kantor menggunakan konfigunasi pengalamatan IP Address static dan jaringan wifi publik menggunakan pengalamatan IP Addess dinamic. Pendistribusian pengalamatan IP Address kantor tidak dapat termonitor dengan benar, dikarenakan pengalamatan secara statis[8]. Ketika suatu komputer kantor terdapat kerusakan operating system sehingga dilakukan installasi ulang, maka pendistribusian IP Address menjadi sulit, hal itu dikarenakan distribusi 
dilakukan secara manual. Masalah akan terjadi jika komputer kantor tidak dikonfigurasi pengalamatan $I P$ Address maka akan otomatis masuk pada jaringan public (akses wifi pengunjung). Pemasangan akses hotspot untuk pengunjung juga akan terkendala dengan model jaringan yang tergambar pada gambar 1[9]. Ketika setup hotspot dilakukan maka akses jaringan private (kantor) akan masuk ke halaman login. Solusi terbaik dilakukan pemetaan ulang seperti pada gambar 3.

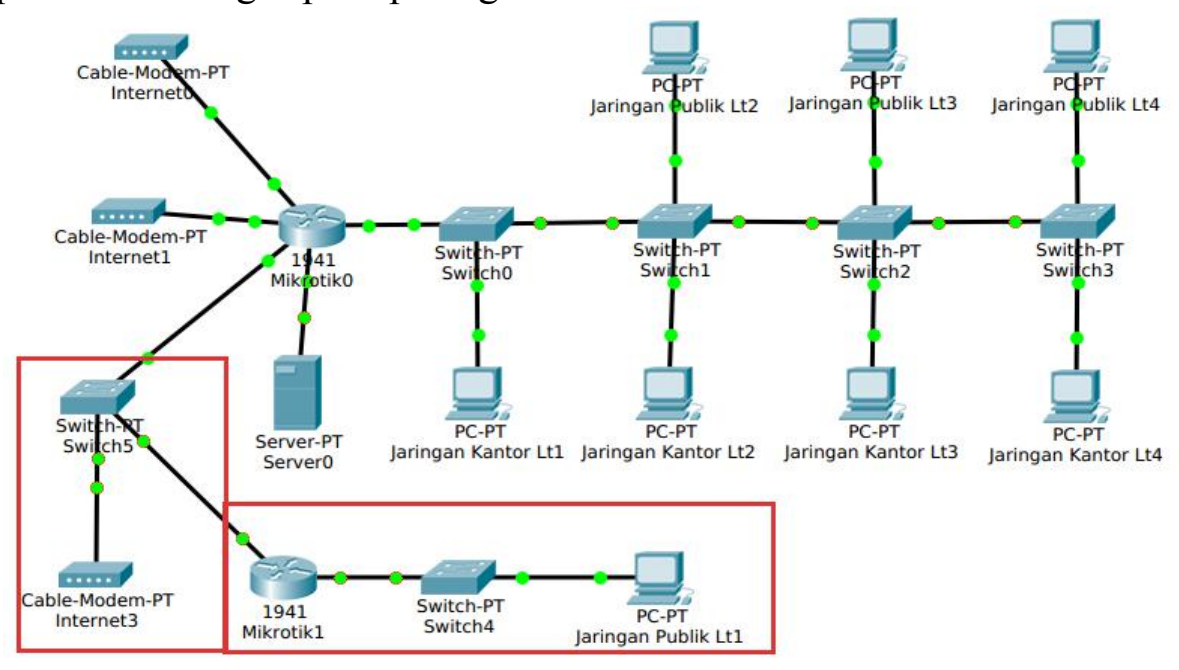

Gambar 3. Pemetaan Awal RSUD Gambiran II

Pemetaan jaringan pada RSUD Gambiran II dilakukan sesuai dengan waktu pelaksanaan. Waktu yang ditentukan untuk pengerjaan teknis selama 3 bulan. Pengerjaan hanya dapat dilakukan pemindahan pada lantai 1. Pengerjaan hanya dapat dilakukan pada lantai 1 dikarenakan pemetaan akses switch yang terpisah hanya ada pada lantai 1 . Koneksi switch lantai 2 hingga lantai 4 sulit dikerjaan dikarenakan hanya ada satu jalur yang menghubungkan antar lantai. Konsep pemindahan akses wifi publik dilakukan dengan konfigurasi perangkat router mikrotik baru tanpa ada konfigurasi pada router mikrotik lama[10]. Konfigurasi akses layanan wifi publik menggunakan perangkat wifi baru dilakukan agar tidak menggangu akses jaringan yang telah ada.

RSUD Gambiran II menggunakan 3 layanan akses internet. Tiga akses layanan internet digunakan untuk layanan akses server, akses internet (kantor dan pengunjung) dan backup akses internet. Konfigurasi pada mikrotik baru (mikrotik1) menggunakan akses modem yang digunakan sebagai layanan backup internet. Hal tersebut dilakukan dikarenakan modem selalu dalam keadaan stanby dan jarang sekali digunakan. Pertimbangan lain dilakukan agar kontrol full akses modem ke-2 dapat digunakan untuk pihak private (kantor). Konfigurasi mikrotik lama (mikrotik0) tetap dapat melakukan backup internet dengan menggunakan modem ke-3, walaupun modem tersebut digunakan oleh mikrotik baru (mikrotik1). Topologi jaringan baru dapat dilihat pada gambar 2 pada garis yang berwarna merah.

\section{B. Konfigurasi Hotspot}

Konfigurasi hotspot hanya dilakukan pada mikrotik1. Konfigurasi yang dilakukan diantaranya[11]:

1. Manajemen IP Address

2. Pengalamatan dinamis akses wifi publik

3. Pengalamatan dinamis akses kabel

4. Konfigurasi hotspot akses wifi publik

5. Manajemen user hotspot

6. Manajemen bandwith hotspot. 
Langkah awal dilakukan manajemen IP adress untuk koneksi 3 jaringan berbeda. Jaringan 1 digunakan untuk berkomunikasi dengan modem ke-3. Jaringan 1 sebagai jalur masuknya akses internet. Jaringan 2 digunakan untuk konfigurasi mikrotik, jaringan ini juga dapat dimanfaatkan akses tanpa melakukan login hotspot. Jaringan 3 digunakan untuk akses layanan publik, dimana jaringan ini dapat dinikmasi oleh pengunjung rumah sakit. Manajenmen perangkat jaringan terdapat pada gambar 4 .

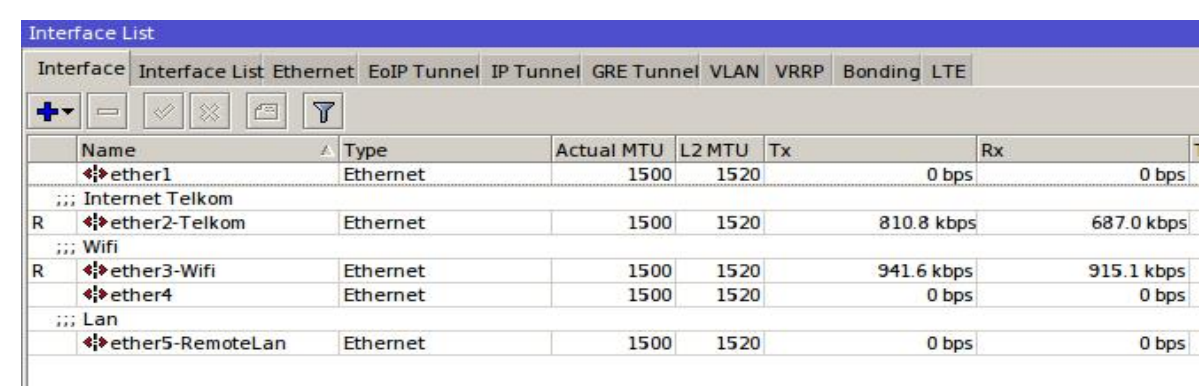

Gambar 4. Interface Router

Langkah selanjutnya dilakukan pengalamatan IP secara dimanis untuk jaringan 2 dan jaringan 3 . Manfaat yang dapat diperoleh yaitu pengguna tidak perlu susah payah untuk menentukan pengalamatan ip secara manual. Konfigurasi dinamis ini juga dilakukan pemetaan alamat statis untuk memudahkan monitoring perangkat yang dimiliki oleh pegawai. Langkah tersebut dapat dilihat pada gambar 3 dan gambar 5 .

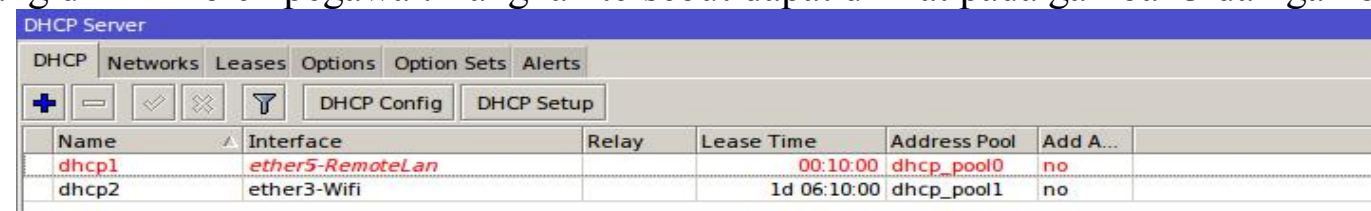

Gambar 5. DHCP Jaringan

Langkah selanjutnya dilakukan konfigurasi hotspot pada jaringan 3. Jaringan hotspot diperuntukkan kepada pengunjung melalui akses gratis. Jaringan hotspot juga dapat dinikmati oleh pegawai dengan akses kecepatan berbeda dengan melakukan registrasi terlebih dahulu. Registrasi digunakan untuk menentukan user dan password untuk akses jaringan hotspot. Penggunaan jaringan hotspot dapat dilakukan manajemen bandwith untuk kelancaran akses internet. Pengalokasian bandwith dapat dilihat pada gambar 6 .

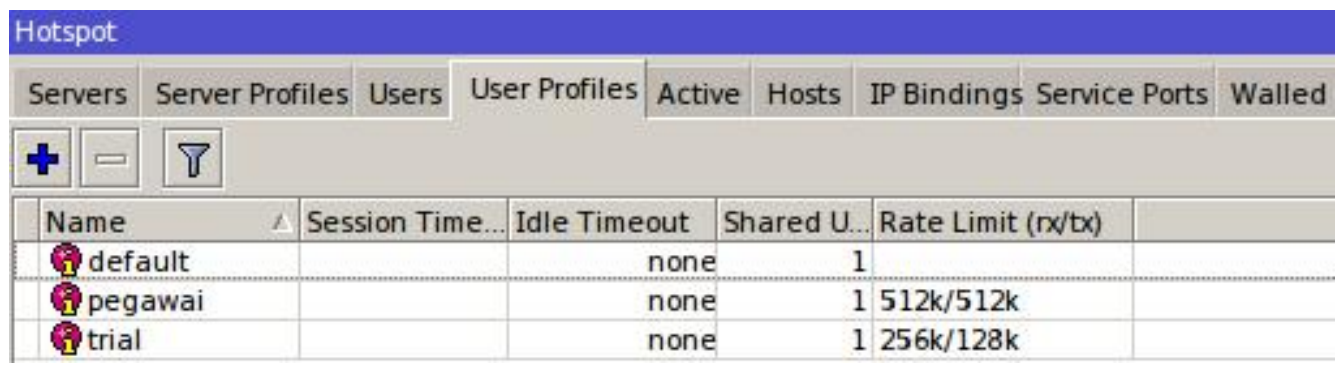

Gambar 6. Manajemen profile

Langkah menambah user hotspot dengan script sebagai berikut:

/ip hotspot user

add disabled $=$ no name $=$ nama_user password $=$ password_user profile=profile_user

Impementasi script user dapat dilihat pada gambar 7. 


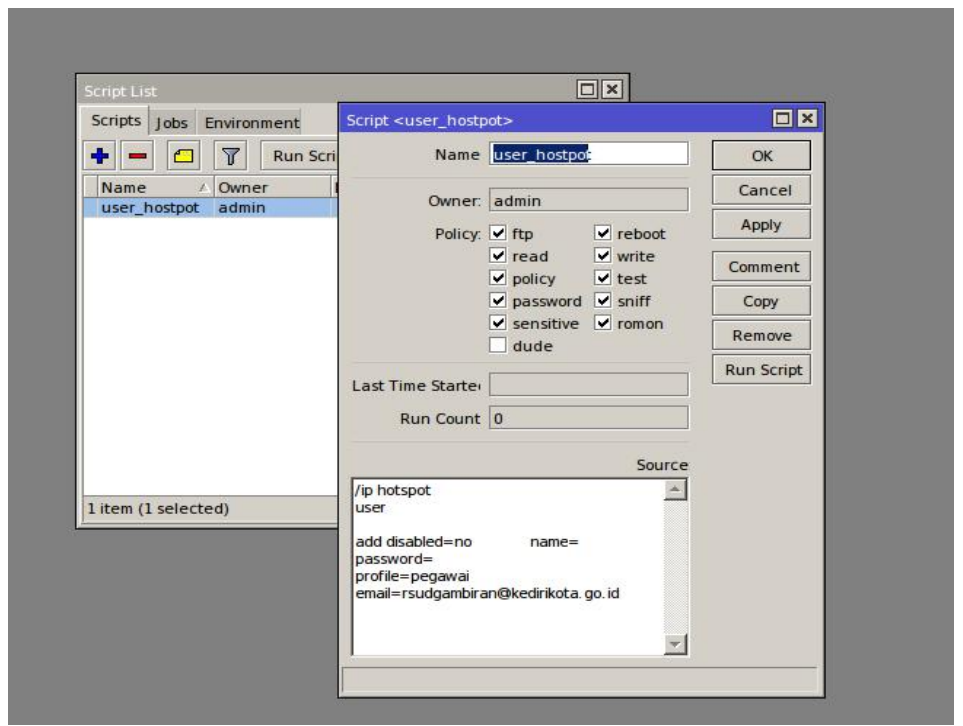

Gambar 7. Script user hotspot

Setelah melakukan Konfigurasi pada Router, Selanjutnya melakukan monitoring pada router untuk memastikan trafik pada jaringan. Pada gambar 8 merupakan hasil dari monitoring jaringan.

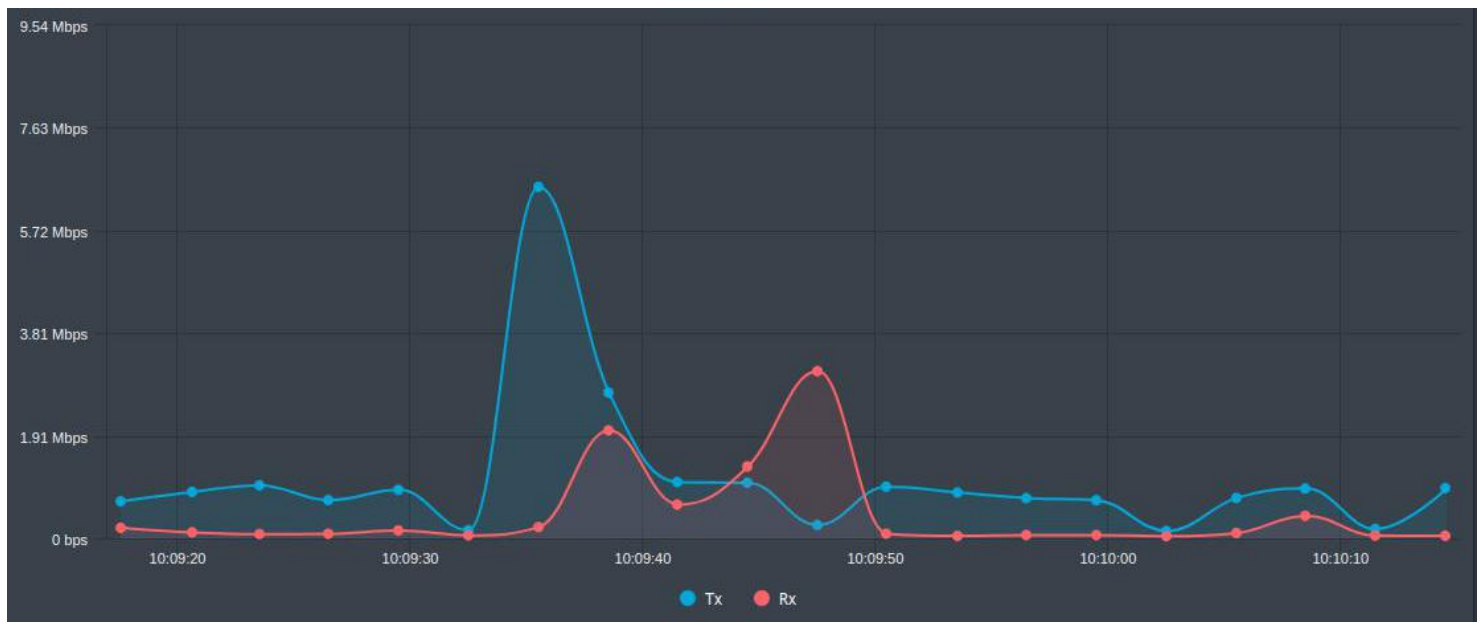

Gambar 8. Monitoring Jaringan.

Hasil Monitoring jaringan menunjukkan akses detail pada jaringan di RSUD Gambiran. Trafik menunjukkan hasil yang stabil. Bandwith yang dimiliki sebesar $30 \mathrm{Mb}$ dan dipakai rata-rata sebesar $2 \mathrm{Mb}$. Hasil yang didapatkan dengan pemindahan akses layanan publik pada lantai satu diharapkan membantu mengurangi beban pada modem ke 2 walaupun masih belum signifikan[12]. Hal tersebut dikarenakan masih banyak pengunjung yang mengakses internet pada lantai 2 sampai lantai 4.

\section{KESIMPULAN}

Pemindahan akses publik menggunakan manajemen hotspot berhasil, Keberhasilan dilihat pada trafik yang ditunjukkan pada gambar 8. Akses pada aplikasi jaringan private seperti pada aplikasi SIMRS telah lancer. Namun pada layanan public seperti pada hotspot layanan umum masih belum efektif karena belum meratanya perangkat wifi dan penyebaran wifi yang dilimili oleh phak RSUD. Faktor tersebut terlihat pada rata-rata pemaiakian yang masih belum optimal yaitu pemaikaian $2 \mathrm{Mb}$ dari total bandwith yang dapat dimanfaatkan sebesar 30Mb. Diharapkan jaringan akses publik lantai2 sampai lantai 4 dapat dipindah ke mikrotik baru (mikrotik1) sehingga dapat memanfaatkan bandwith 30Mb. 
ANTIVIRUS: Jurnal Ilmiah Teknik Informatika (p - ISSN: 1978 - 5232; e - ISSN: 2527 - 337X)

Vol. 13 No. 2, November 2019, pp. $72-79$

\section{DAFTAR PUSTAKA}

[1] D. Kurnia, S. Ramadhani, and S. Supiyandi, "RANCANG BANGUN JARINGAN MENGGUNAKAN MODE PPOE CLIENT MIKROTIK DAN METODE PCQ DI JARINGAN INTERNET SMA NEGERI 20 MEDAN," Comput. Eng. Sci. Syst. J., vol. 3, no. 1, p. 28, Jan. 2018.

[2] W. Odom, Computer Networking first-step. Cisco Press, 2004.

[3] Wahidin, Jaringan Wireless untuk Orang Awam. Yogyakarta: Maxikom, 2008.

[4] S. Aji, "Pengenalan Internet dan Jaringan Komputer," Jakarta PT. Elexmedia Comput., 2005.

[5] M. E. (Mac E. Van Valkenburg, Network analysis. Prentice-Hall, 1974.

[6] M. L. Herlambang and C. L. Azis, "Panduan Lengkap Menguasai Router Masa Depan Menggunakan Mikrotik RouterOS," Yogyakarta ANDI Publ., 2008.

[7] J. FitzGerald and A. Dennis, Business data communications and networking. John Wiley \& Sons, 2007.

[8] S. Sujalwo, B. Handaga, and H. Supriyono, "Manajemen Jaringan Komputer dengan Menggunakan Mikrotik Router," Komuniti J. Komun. dan Teknol. Inf., vol. 2, no. 2, pp. 32-43, 2011.

[9] R. Adrian, "Optimasi Cost pada Open Shortest Path First di Jaringan Software Defined-Network," Techno.Com, vol. 16, no. 4, pp. 421-434, Sep. 2017.

[10] M. F. Duskarnaen and F. Nurfalah, "Analisis, Perancangan, Dan Implementasi Jaringan Wireless Point To Point Antara Kampus A Dan Kampus B Universitas Negeri Jakarta," PINTER J. Pendidik. Tek. Inform. dan Komput., vol. 1, no. 2, pp. 134-141, Dec. 2017.

[11] A. Hidayat, "Design of Radius Server on Server Network Internet Faculty of Computer Science University Muhammadiyah Metro," Int. J. Inf. Syst. Comput. Sci., vol. 2, no. 1, pp. 13-29, 2018.

[12] M. F. Nadhif, R. Indriati, and Sucipto, "Arsitektur Manajemen Bandwidth Menggunakan Metode Queue Tree," in Seminar Nasional Inovasi Teknologi, 2019, pp. 145-150. 